\title{
The Tropospheric Response to the Passage of Solar Sector Boundaries
}

\author{
By Yukio Misumi \\ Geophysical Institute, Kyoto University, Kyoto 606, Japan \\ (Manuscript received 21 May 1982, in revised form 16 June 1983)
}

\begin{abstract}
The effect of the passage of solar sector boundaries (SSB) on the variation of zonal mean fields below the $100 \mathrm{mb}$ level is investigated for the period from November 1963 to March 1978. From a key-date analysis it is found that the polar temperature in the troposphere reaches a minimum on the passage date of SSBs during winter in the period from December 1964 to February 1972. At the $500 \mathrm{mb}$ level of the North Pole, the filtered temperature on the passage date deviates $-2.59 \mathrm{~K}$ from the mean. Such a large deviation as $-2.59 \mathrm{~K}$ was not obtained in the random sampling of key dates. This response appears in each of 8 winters from 1965 to 1972 and each of 3 months in winter.
\end{abstract}

\section{Introduction}

For a long time, the existence of long-term correlations between the solar activity (e.g., sunspots numbers) and some quantities of the atmosphere has been insisted by many authors. Their time scales are 11-years, 22-years, and hundreds years. Recently, as observations of the Sun and the interplanetary space are increased, short-term Sun-weather relations have been interested in. In addition to the studies of extraordinary events on the Sun and the interplanetary space, such as the solar flare and the geomagnetic storm (see Chapter 4.1, 4.2 of Herman and Goldberg (1978), for example), the effect of the periodic variation of the solar activity due mainly to the solar rotation has been investigated in different ways: One is the study to use the $10.7 \mathrm{~cm}$ solar radio flux as a measure of the solar activity, and the estimation is made of the cross correlation between the $10.7 \mathrm{~cm}$ flux and various atmospheric quantities, for example the zonal wind (Nastrom and Belmont, 1978), the circulation index (Ebel and Baetz, 1977), and the planetary wave (Ebel et al., 1981). However, all of them are limited in the stratosphere and mesosphere. The other is, while limited mainly in the troposphere, to use dates of the solar sector boundary passing through the Earth as key dates and superpose atmospheric quantities. (The interplanetary magnetic field (IMF) around the equatorial plane, which has 2 or 4 sectors changing slowly, rotates with the Sun, so boundaries of the sectors called solar sector boundaries (SSB) pass through the Earth quasi-periodically. (see Fig. 2).

Wilcox et al. (1974) reported that the vorticity area index (VAI), defined as a trough index (Roberts and Olson, 1973), and summed over northern part of $20^{\circ} \mathrm{N}$ reaches a minimum on the first day after the passage of SSBs, and this variation occurs in the upper troposphere during the winter months from November to March in the period from 1964 to 1970 . Wilcox et al. (1976) also found the same minimum in the period from 1963 to 1974 . Their result was supported by Shapiro (1976) and Hines and Halevy (1977) by using various statistical methods. Moreover, the response of the forecasting accuracy of the VAI (Larsen and Kelly, 1977) and the VAI in the Southern Hemisphere (Burns et al., 1980) were studied.

However, there still remain some problems about the VAI response. Williams and Gerety (1978) showed that the minimum of the VAI is not evident for the period from 1974 to 1977 . Although Wilcox and Scherrer (1979) considered that there happened some changes in the tropospheric circulation system, verification of this idea is difficult, because the physical meaning of the VAI in the atmospheric dynamic process is not established yet. 
Therefore, for the purpose of investigating the guiding process of the solar effect on the troposphere, it is desirable to find the response of other quantities directly related to the atmospheric dynamics. Williams (1978) examined the variations of four conponents of the Lorenz's energy cycle summed over northern part of $20^{\circ} \mathrm{N}$ around passages of SSBs. He found the variation of the eddy kinetic energy (KE), which is qualitatively connected with that of the VAI, but that of $\mathrm{KE}$ was not so statistically significant. Williams and Gerety (1980) found the more significant variation of the kinetic energy in wave number 5, but they did not give a plausible explanation why the only one wave responds to the passage of SSBs and why the response is absent after 1974.

In order to see the nature of the response in terms of atmospheric dynamics, in this study we investigate responses of zonal mean fields of temperature and height in the Northern hemisphere to the passage of SSBs.

\section{Data and method}

We use the National Meteorological Center (NMC) gridpoint data for temperature and height fields twice a day (00 and 12 GMT) from 1963 to 1978 at the 1000 (height only), 850, 700, 500, $300,200,150$, and $100 \mathrm{mb}$ level. From 1965 to 1978 the 250 and $400 \mathrm{mb}$ level data are added. Zonal mean values $(\bar{H}, \bar{T})$ are obtained at every 5 degrees in latitude from $20^{\circ} \mathrm{N}$ to the North Pole. These zonal means are filtered $\left(\bar{T}^{*}, \bar{H}^{*}\right)$ to remove the variation with time scales irrelevant to the solar rotation. The frequency response of the filter is shown in Fig. 1. These filtered data are mainly used in this study for the purpose of avoiding the seasonal trend in the superposed result, which is not an object of this study and usually dominantes when the used passages are accidentally biased to a particular time of the year or the passages in a particular time of the year are investigated.

A superposed epoch analysis with an interval of 32 days centered on each key date is applied to the filtered data. Key dates are passage dates of SSBs, which are mainly determined as the nearest date ( 00 or $12 \mathrm{GMT}$ ) from the reversal time of the IMF with an interval of more than 5 days from both adjacent reversal times of the IMF. Reversal times of the IMF are obtained from the IMF hourly value of NASA/NSSDC by satellites when they are available. In order

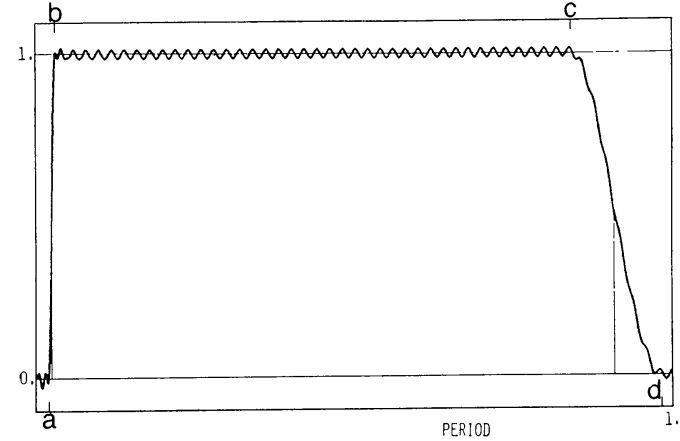

Fig. 1 Resultant frequency responses of the filter used in this study, which is arranged after Hasebe (1980). Abscissa indicates period in day. a), b), c), and d) denote 50.0, $33.33,1.18$ and 1.02 day period.

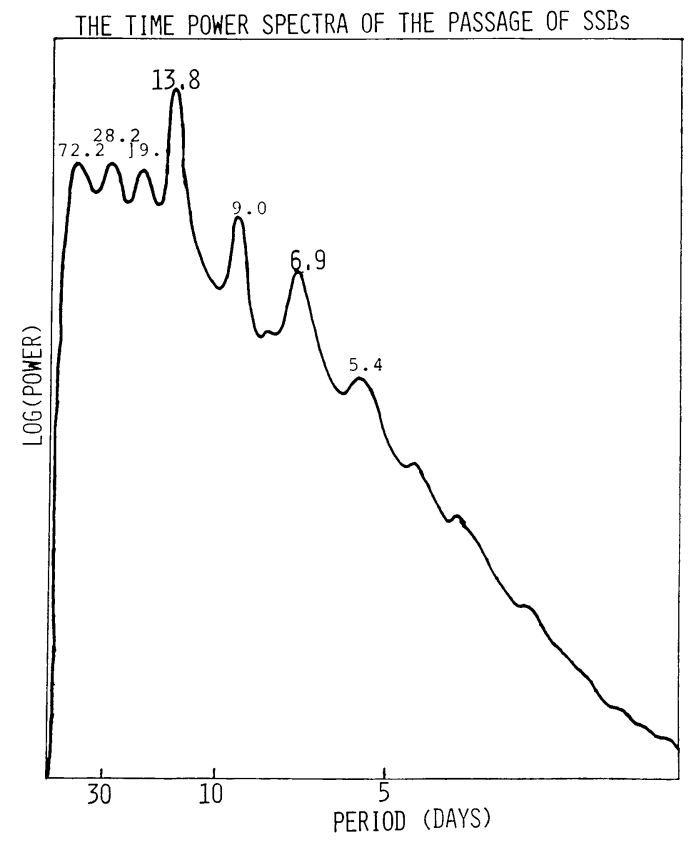

Fig. 2 Time power spectra of our selecting passage of SSBs in the period from December 1964 to December 1972. The period of some peaks are written. This calculation considers one interval of SSBs as one cycle.

to cover the period when satellites data are missing, for example March 1964-May 1965, we use the list of the interplanetary magnetic field by Svalgarrd (1976), which is inferred by the ground-based observation and is daily data. (The difference of two types data is discussed in 3-6.) Passage dates of SSBs from both data cover the period from November 1963 to March 
1978. Figure 2 shows the time power spectra of them. A significant peak is located at the 13.8 day period. It can be seen from Fig. 2 that the passage of SSBs is a quasi-periodic phenomenon with an half cycle of the solar rotation, and the 2 -sector structure is perhaps dominant in this period. As has been already mentioned in early studies of this subject (Wilcox et al., 1976; Williams 1978), we suppose that the response raises not from the reverse of the interplanetary magnetic field itself but from changes of some quantities peculiar to SSBs, $K_{p}$ index (Wilcox and Colburn, 1972) and UV irradiance (Heath et al., 1975) for example.

As a measure of relative significance of deviations in many superposed results, we calculate Student's $t$-value, i.e. deviation from the mean divided by the r.m.s. In practice $t(j)$, the $t$-value on the $j$-th half-day from the key date, is given as follows:

$$
t(j)=\frac{\left.(\overline{X(i, j)})^{i}-X(\overline{i, j})^{i j}\right) N^{1 / 2}}{\left(\bar{X}(\overline{i, j})^{\overline{2} i}-\left(\bar{X}(\bar{i}, \bar{j})^{i}\right)^{2}\right)^{1 / 2}},
$$

where $X(i, j)$ is the value under consideration on the $j$-th half-day from th $i$-th key date, $N$ is the number of used key dates and the bar denotes the average over the superscript.

As regards the season, we define four seasons as summer (June-August), autumn (SeptemberNovember), winter (December-February) and spring (March-May). For simplicity we call the winter from December 1963 to February 1964 as winter of 1964 and so on.

\section{Results}

\subsection{Overall picture}

A very significant response to the passage of SSBs that appears most clearly in the tempera-
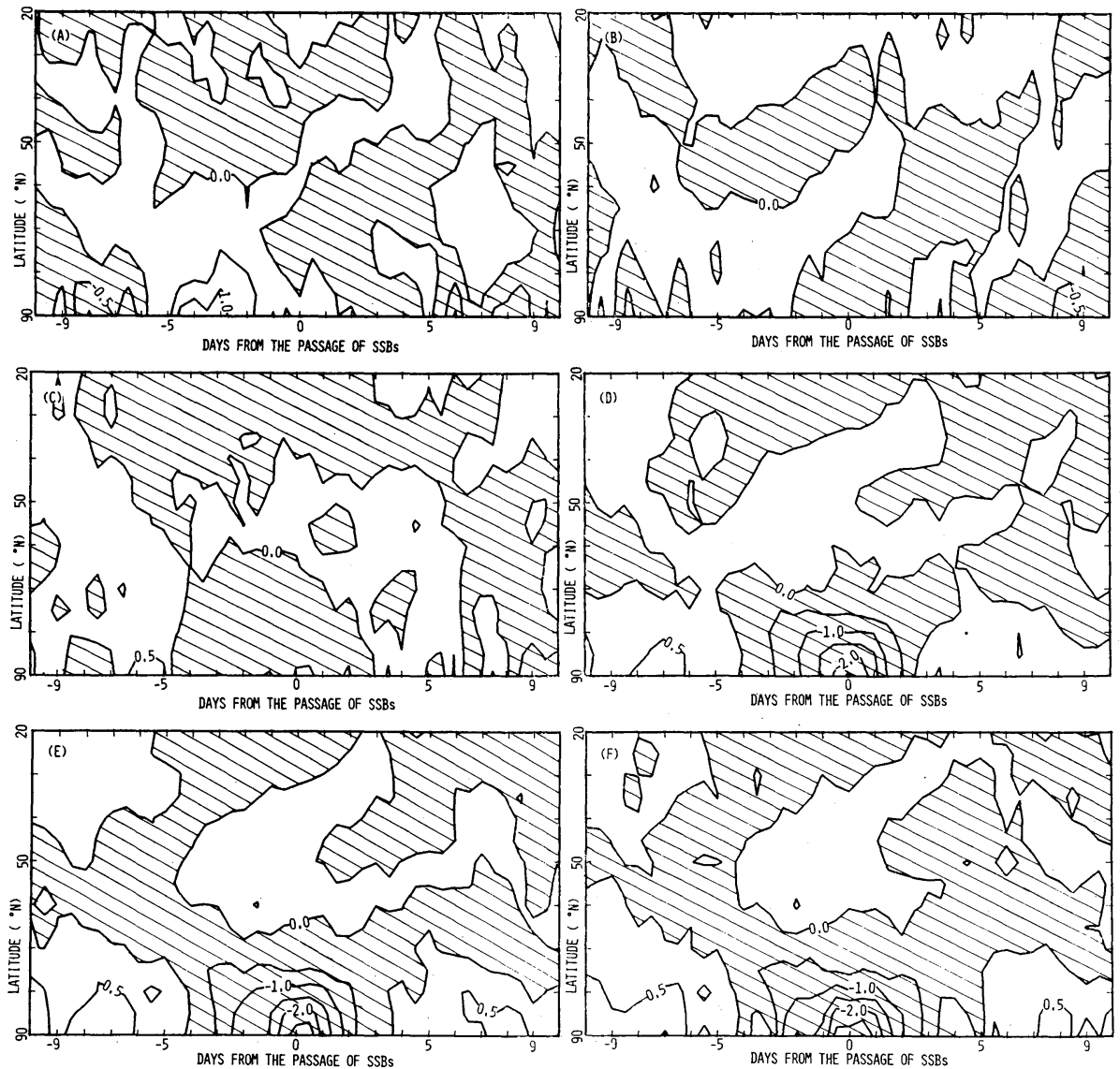

Fig. 3 The time-latitude cross section of $\bar{T} *$ around the passage of SSBs, at (A) $100 \mathrm{mb}$, (B) $200 \mathrm{mb}$, (C) $300 \mathrm{mb}$, (D) $500 \mathrm{mb}$, (E) $700 \mathrm{mb}$ and (F) $850 \mathrm{mb}$. 43 passages of SSBs occuring in winter in the period from December 1964 to February 1972 are used. The area where $\bar{T} *$ is negative is hatched, and the interval of lines is $0.5 \mathrm{~K}$. 
ture field is found in the polar region. Figure 3 shows variations of the filtered zonal mean temperature $\left(\bar{T}^{*}\right)$ at 6 levels $(100,200,300,500$, 700 and $850 \mathrm{mb}$ ), superposed on 43 passages of SSBs in winter in the period from December 1964 to February 1972. The polar temperature reaches a minimum on the 0 -th or first half-day after the passage of SSBs below the $500 \mathrm{mb}$ level, and this variation spreads to $70^{\circ} \mathrm{N}$. On the contrary, at the 300, 200 and $100 \mathrm{mb}$ levels no such variation is found.

The value of the minimum at $90^{\circ} \mathrm{N}$ and at each level (Numbers in parentheses are $t$-values.) is $-2.59 \mathrm{~K}(-6.49)$ on the 0 -th half-day at the $500 \mathrm{mb}$ level, $-2.86 \mathrm{~K}(-6.12)$ on the 0 -th at the $700 \mathrm{mb}$ and $-3.02 \mathrm{~K}(-5.14)$ on the first at the $850 \mathrm{mb}$. The largest change of $\bar{T}^{*}$ appears on the first half-day at $90^{\circ} \mathrm{N}$ at the $850 \mathrm{mb}$ level. Judging from the magnitude of $t$-value, the variation on the $500 \mathrm{mb}$ level is most significant. The distribution of $t$-value on the $500 \mathrm{mb}$ level is shown in Fig. 4, which shows that the polar temperature variation is the most significant as well as the largest.

Figure 5 shows the anomaly of the zonal mean geostrophic wind on the passage date. The westerly anomaly region centered at $82.5^{\circ} \mathrm{N}$ at the $300 \mathrm{mb}$ level exists in the northern part of $40^{\circ} \mathrm{N}$, as can be expected from Fig. 3 through the thermal wind relation. The most significant $t$-value, which appears at $87.5^{\circ} \mathrm{N}$ at the $150 \mathrm{mb}$ level, is 4.36 , so that this westerly anomaly is remarkable, but the variation can be seen more significantly in the temperature field. We can see in $20-40^{\circ} \mathrm{N}$ region, where $\bar{T}^{*}$ has no marked variation, the easterly anomaly region centered at $32.5^{\circ} \mathrm{N}$ at the $200 \mathrm{mb}$ level with the most significant $t$-value is -2.55 . In the zonal

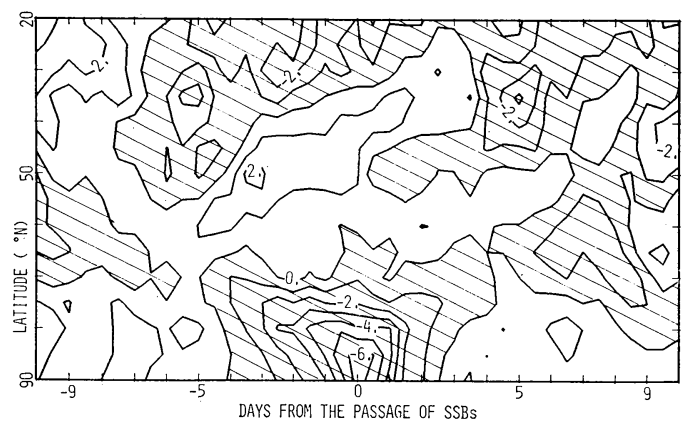

Fig. 4 The time-latitude cross section of $t$ value of Fig. 3(D). The interval of lines is 1. The areas where $t$-value is negative are hatched.

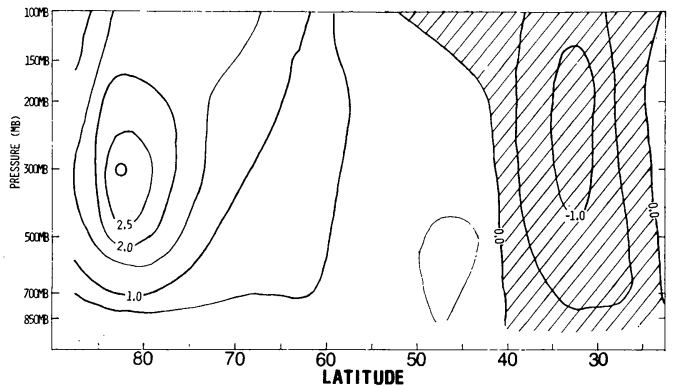

Fig. 5 The latitude-height cross section of the anomaly of the zonal mean geostrophic wind on the passage date of SSBs which are as same as that in Fig. 3. The filtered zonal mean height $(\bar{H} *)$ is used to calculate the zonal mean geostrophic wind. The easterly anomaly region is hatched and the interval of lines is $0.5 \mathrm{~m} / \mathrm{sec}$.

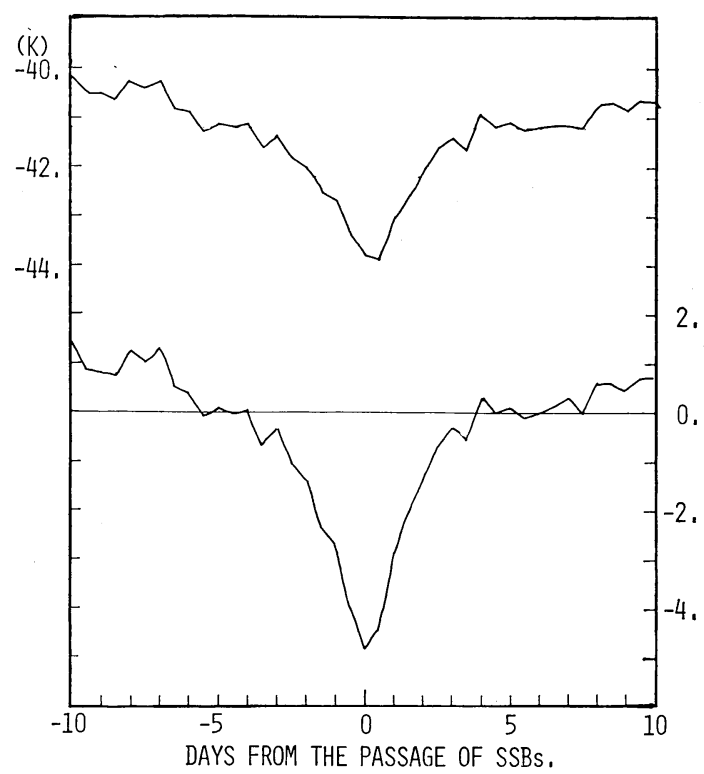

Fig. 6 The variation of the raw temperature, i.e. $\bar{T}$, (above) and its $t$-value (below) at the $500 \mathrm{mb}$ level at $90^{\circ} \mathrm{N}$ around the same passage of SSBs as Fig. 3.

mean wind field, the variation also appears mainly in the polar region as the temperature field does, but it extends all over the Northern Hemisphere and to the lower stratosphere.

For reference, the variaion of the raw data $(\bar{T})$ around the passage of SSBs is shown in Fig. 6. There remains only negligible seasonal trend, so the minimum on the passage date is remarkable. This is a special case, usually the seasonal trend in the superposed result is too large to 
study the variation of shorter time scales around the passage of SSBs.

\subsection{Statistical significance}

$t$-values at the 850,700 and $500 \mathrm{mb}$ are too large to happen by chance, but the statistical significance level defined by $t$-value is not strictly correct unless the data form a normal distribution. In order to remove this defeat, the random sampling of key dates is performed, as was done by Hines and Halevy (1977) and Williams (1978), by which the statistical significance level can be defined on the basis of the actual distribution of $\bar{T}^{*}$. A result of the random sampling of key dates is shown in Fig. 7. Such a large deviation as $\bar{T}^{*}$ value on the 0 -th half-day at $90^{\circ} \mathrm{N}$ in Fig. 3 (D) does not appear in this random sampling of key dates. This means that the statistical significance level of the polar $\bar{T}^{*}$ variation is beyond $99.9 \%$. Therefore we consider that this variation can never be expected by chance but shows the evidence of a response to the passage of SSBs.

In what follows, we show features of this response. Though we only show results for some specified levels and latitudes, similar features can be found wherever the response can be found.

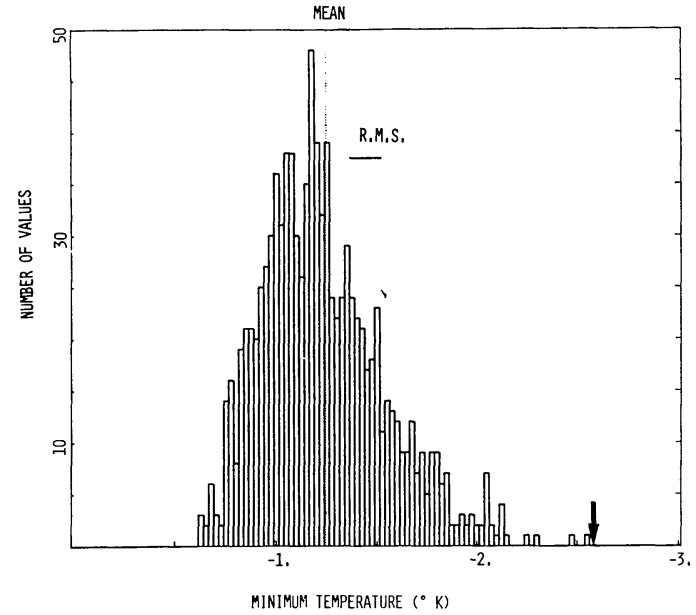

Fig. 7 Distribution of minimum values at $90^{\circ} \mathrm{N}$ at the $500 \mathrm{mb}$ level in 1000 times of random sampling of key dates. In each sampling, 43 key dates separating over 5 days each other are selected randomly from winter from 1965 to 1972 . The mean (vertical dotted line) is $-1.24 \mathrm{~K}$, r.m.s. (horizontal bars) is $0.31 \mathrm{~K}$, and $\bar{T}^{*}$ on the passage date at $90^{\circ} \mathrm{N}$ in Fig. 3(D), which is $-2.59 \mathrm{~K}$, is by an arrow.

\subsection{Long-term and seasonal variation}

$\bar{T}^{*}$ and its $t$-value on the 0-th half-day of each winter at $90^{\circ} \mathrm{N}$ at the $500 \mathrm{mb}$ level are shown in Fig. 8. On the 0-th half-day, value of $\bar{T}^{*}$ in winters from 1964 to 1972 are always negative. Judging from the magnitude of $t$-value, most of them are remarkable with the exception of 1964 , but after 1973 values of $\bar{T}^{*}$ on the 0 -th half-day are at random and none of them is remarkable.

Figure 9 shows latitude-time cross sections of $\bar{T}^{*}$ at the $500 \mathrm{mb}$ level around the passage of SSBs in each month in the period from December 1964 to February 1972. Values of $\bar{T}^{*}$ in the polar region have a depression just after the passage of SSBs in January, February, March and December. In other months no such depression is found. Judging from the magnitude of $t$-value the most significant depression appears at 85 or $90^{\circ} \mathrm{N}$ in each of three months, each one being -5.02 in January, -4.82 in February and -4.80 in December, and that of March, -2.00 , appears at $85^{\circ} \mathrm{N}$. The response in March isn't so significant as that in December, January, and February. The magnitude, and the time and latitudinal structure of the depression in January, February and December are similar to each other, indicating that the response occurs equally in winter. The response needs some at-

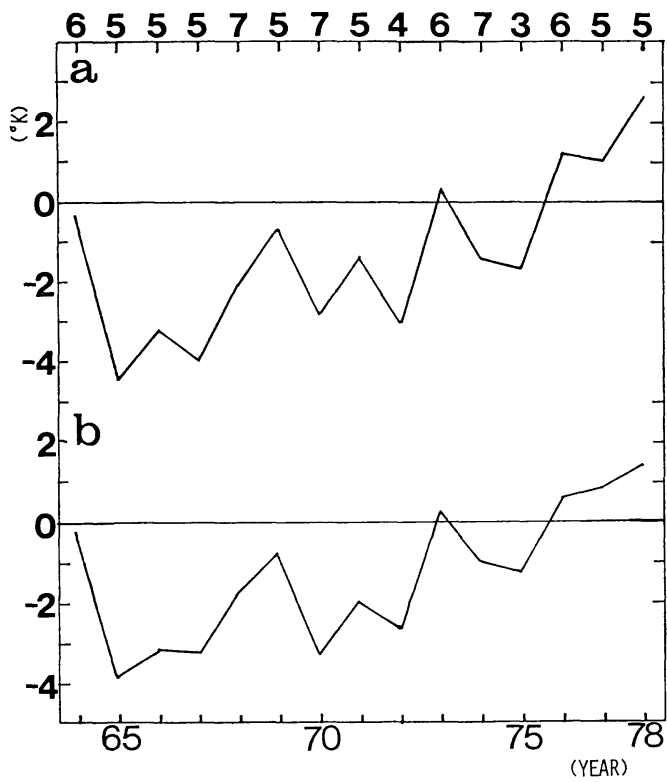

Fig. $8 \bar{T}^{*}$ (a) and its $t$-value (b) on the passage date at $90^{\circ} \mathrm{N}$ at the $500 \mathrm{mb}$ level in each winter, and the number of passages of SSBs in each winter is written above. 

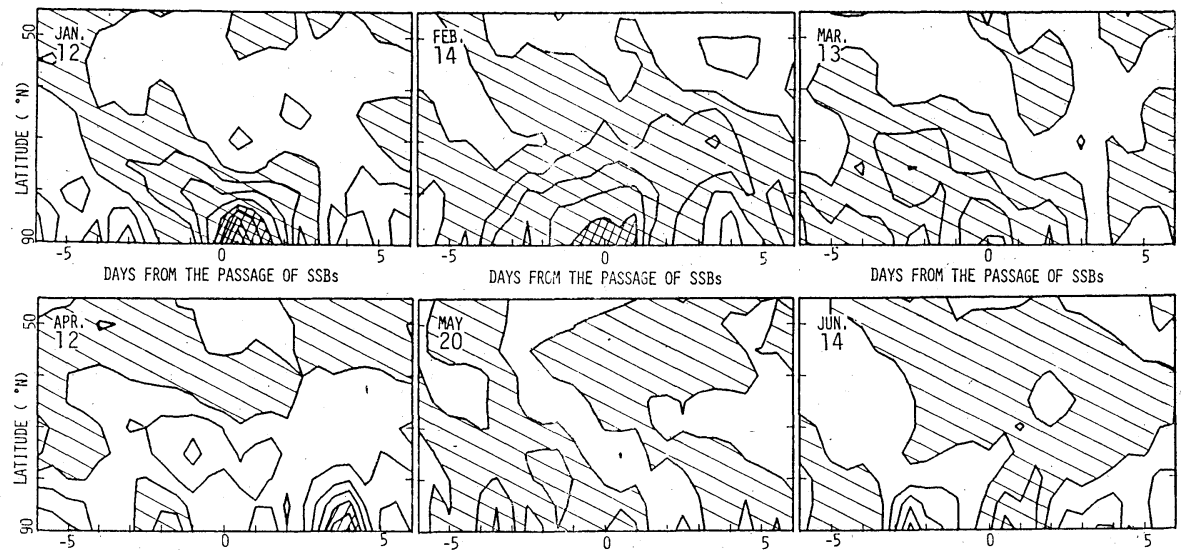

DAYS FROM THE PASSAGE OF SSBS

DAYS FROM THE PASSAGE OF SSBS

DAYS FROH THE PASSAGE OF SSDS
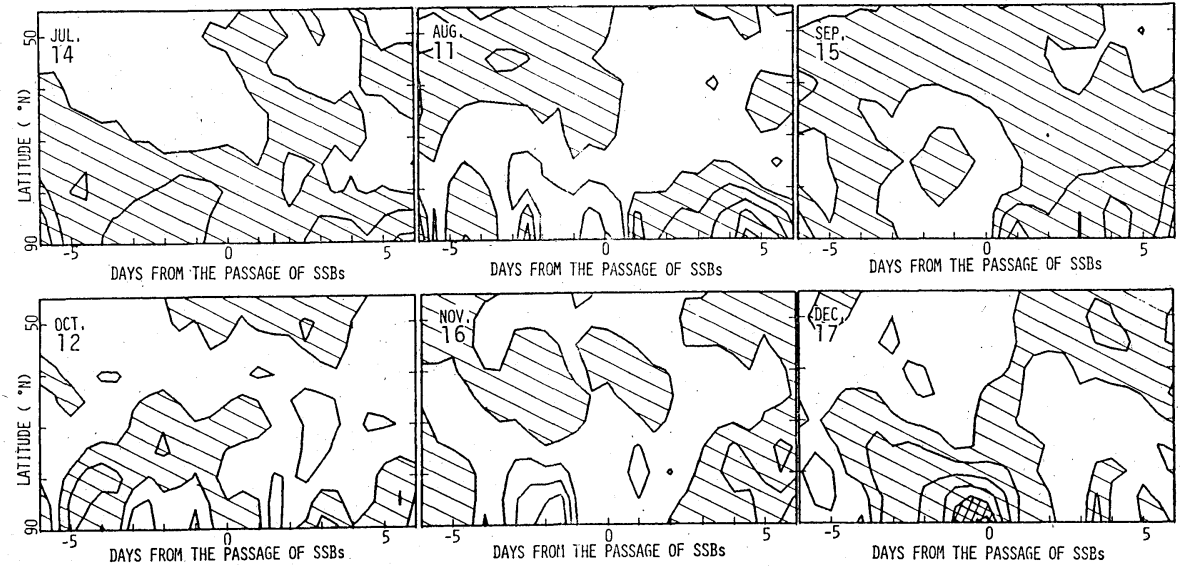

Fig. 9 Time-latitude cross sections of the $\bar{T}^{*}$ at the $500 \mathrm{mb}$ level around the passage of SSBs in each month. Each cross section uses the passage of SSBs, number of which is written in the left side, occurring in the month in the period from October 1964 to June 1972. The interval of lines is as same as that of Fig. 3. The area where $\bar{T}^{*}$ is negative is hatched and where $\bar{T}^{*}$ is lesser than $-2 \mathrm{~K}$ is also crosshatched.

mospheric states which continue only in winter. Perhaps these states remain untill the first half of March, so that a weak response appears in March.

\subsection{Vertical structure}

Figure 10 shows the time-height cross section of the response at $90^{\circ} \mathrm{N}$. The response disappears above the $300 \mathrm{mb}$ level and the response remains remarkable in the thickness between $400-300 \mathrm{mb}$ (not shown in this paper). Therefore the response is confined in the troposphere. The magnitude of the response increases, and the date of the response is delayed, gradually with decreasing height.

\subsection{Length of the sector}

In this subsection, we discuss relationships be- tween the length of the sector, i.e. the interval of the passage of SSBs, and the response. We divide the passage of SSBs occuring in winter in the period of December 1964 to February 1972 into groups according to their intervals to adjacent passages. Figure 11 shows the response on the passage date to each group. The value of the $i$-th half-day represents $\bar{T}^{*}$ at $90^{\circ} \mathrm{N}$ at the $500 \mathrm{mb}$ level on the passage date of SSBs which are separated over $i-2$ half-days from both of adjacent passages and under $i+2$ half-day from either of them. The passage of SSBs with intervals shorter than 10 half-day causes little response. This is the reason why we exclude the passage of SSBs with intervals shorter than 5 days from our passage data. The 10 half-days forms a kind of the critical interval, which seems 


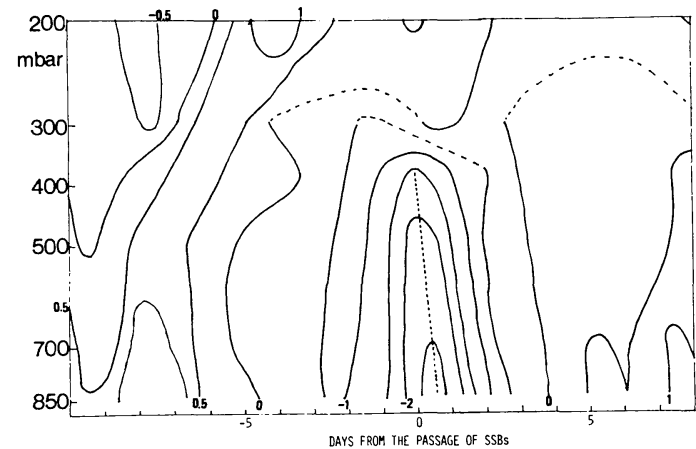

Fig. 10 The time-height cross section of the $\bar{T} *$ at $90^{\circ} \mathrm{N}$ around the passage of SSBs. For the purpose of adding to results at the 400 and $250 \mathrm{mb}$ levels, this analysis uses only 39 passages of SSBs occuring in winters from 1966 to 1972 . The interval of thick lines is $0.5 \mathrm{~K}$ and that of thin lines $0.25 \mathrm{~K}$. The vertical dotted line denotes the maximum amplitude phase at each level.

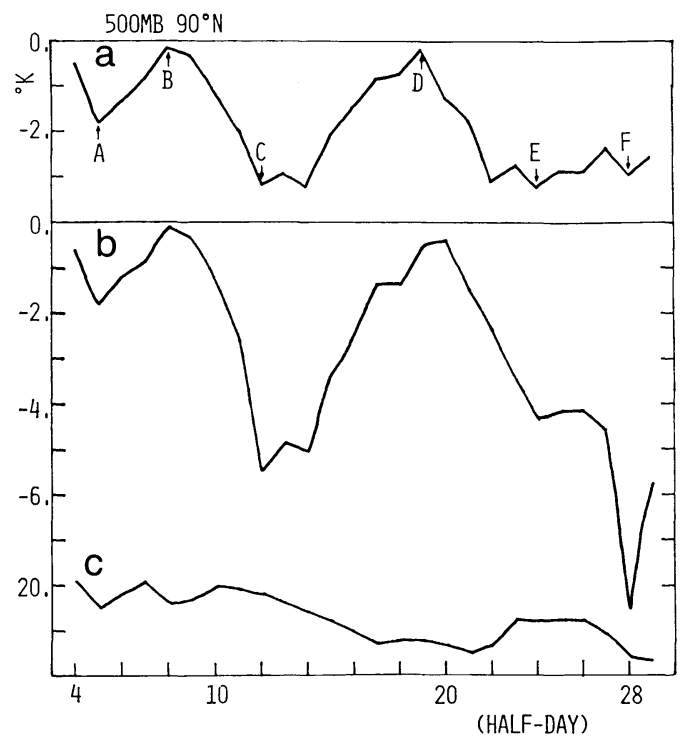

Fig. $11 \bar{T} *$ (a), $t$-value (b) at $90^{\circ} \mathrm{N}$ at the $500 \mathrm{mb}$ level on the passage date, and the number of the passage (c), of SSBs, of which the interval is limited among 5 days centered on the half-day at the abscissa. All passages of SSBs occurs in 8 winters from 1965 to 1972 .

to be determined by the time scale of the response in the atmosphere, because the variation of the interplanetary space on the passage of SSBs with intervals shorter than 10 half-days is
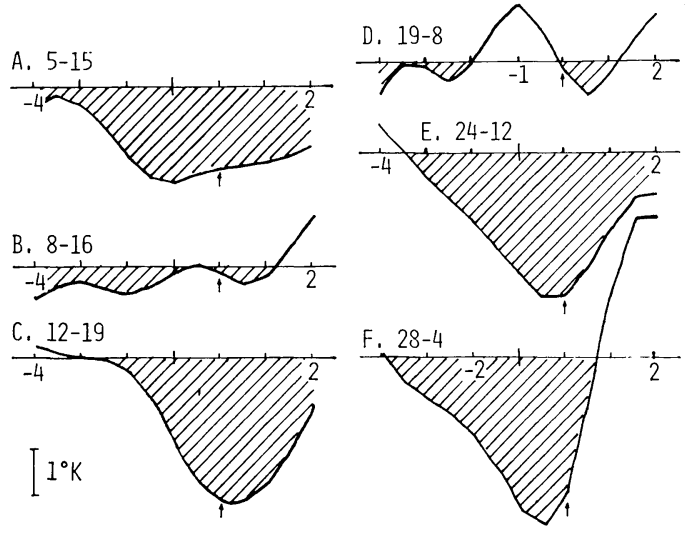

Fig. 12 The variation of $\bar{T} *$ at $90^{\circ} \mathrm{N}$ at the $500 \mathrm{mb}$ level around the passage of SSBs in 6 groups, which are shown as alphabets in Fig. 11. The half-day centering at each group and the number of included passages of SSBs are listed in the upper left. The abscissa is days from the passage date indicated by the arrow, and the negative $\bar{T} *$ is hatched.

almost equal to those on the passage of other SSBs.

The large response appears the 10-14 half-day interval and the 22-26 half-day interval, where the number density of the passage of SSBs is large. The former corresponds to the typical interval in the 4-sector structure of the IMF, and the latter in the 2-sector structure.

Figure 12 also shows the full response to 6 groups indicated by the alphabet in Fig. 11. If we compare $C$ (an example of the 10-14 halfday interval) with $\mathrm{E}$ and $\mathrm{F}$ (the 22-26 half-day interval), the response in the latter seems to occur ealier than that in the former. On the assumption that the response occurs early as the length of the sector increases, we consider that the response results from a condition on the Sun satisfied in the latter part of the sector as a forerunnner of the passage of SSBs, the appearance period of which has a little positive relation with the length of the sector.

\subsection{Others}

Here, we compare the response to the passage of SSBs from the direct observation of the IMF by the satellite, and to the passage of SSBs from the ground-based indirect observation. The period of comparison is 7 winters from 1966 to 1972 , during which the satellite observation is continuously operated, and both observations in- 
clude the same number of 36 passages of SSBs. Figure 13 shows the response to the passage by the ground-based observation and to the passage by the satellite observation, and also shows the response to the passage by the satellite observation with a resolving interval of $24 \mathrm{~h}$, which is as same as that of the ground-based observation. The response to the passage by the groundbased observation appears but is not significant, (in our random selection of key dates, $\bar{T}^{*}$ on the passage date at $90^{\circ} \mathrm{N}$ at the $500 \mathrm{mb}$ level $(-1.42 \mathrm{~K})$ deviates only 0.75 r.m.s. from the mean.). On the other hand, that to the passage of SSBs by the satellite observation with the resolving interval of $24 \mathrm{~h}$ is adequately significant. The fact that only the satellite observation clearly shows the response also seems to reinforce the significance of our conclusion, because the satellite observation is more accurate and correct than the ground-based one. On the other hand this fact makes it difficult to extend the investigation period because the satellite observation is operated during the very limited period.

\section{Concluding remarks}

Throughout the key date analysis, we found that the temperature in the polar troposphere has a tendency to reach a minimum on the 0 -th or

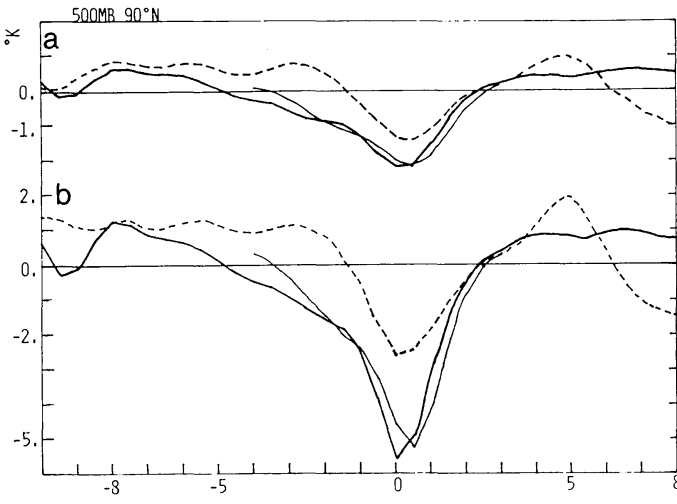

DAYS FROM THE PASSAGE OF SSBS

Fig. 13 Variations of $\bar{T} *$ (a) and $t$-value (b) at $90^{\circ} \mathrm{N}$ at the $500 \mathrm{mb}$ level around 36 passages of SSBs, which are selected from the satellite data with resolving intervals of $12 \mathrm{~h}$ (thick line), with intervals of $24 \mathrm{~h}$ (thin line), and are listed in Svalgarrd (1976) whose resolving interval is $24 \mathrm{~h}$ (broken line). All passages of SSBs occurs in winters from 1966 to 1972 , in which both data are available.

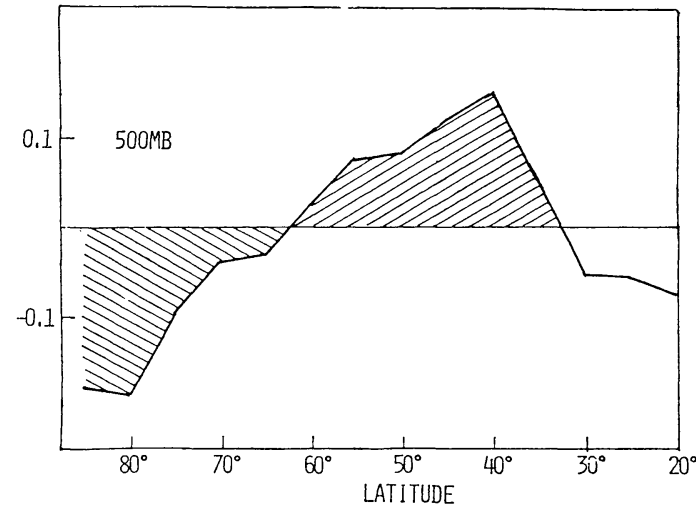

Fig. 14 The latitudinal distribution of $\bar{T} * \cos$ $\theta$ on the passage date at the $500 \mathrm{mb}$ level in Fig. 3. $\theta$ is latitude.

first half-day after the passage of SSBs in winter. It is concluded that the response has not only excellent high statistical credibility but also systematic features in the period from December 1964 to February 1972.

In considering the mechanism for the response, Figure 14 gives a suggestion. Figure 14 shows changes of $\bar{T}^{*}$ taken the area of each latitude into consideration. The whole heating in middle latitudes $\left(60-35^{\circ} \mathrm{N}\right)$ is almost equal to the whole cooling in the polar region $\left(90-65^{\circ}\right)$ at each level. The response in the polar region must result from a change of the northward heat transfer around $60^{\circ} \mathrm{N}$, most of which is contributed by eddy heat fluxes. The relation between the change of the VAI reported by Wilcox et al., which must be a index of the eddy field, and the response in the polar temperature should be interested.

At the present stage, we can't give an answer to the problem why the response is absent after 1973. However, it must be a valuable basis of the investigation of the sun-weather relation that one stage of a sun-weather relation is described by the most fundamental atmospheric quantities. The study of the response in terms of wave activities will be presented in future.

Though our study is mainly limited in the atmospheric process, it is indispensable to search for what kind of the variation on the Sun and in the interplanetary space causes this response.

\section{Acknowledgements}

The auther wishes to express his hearty thanks to Prof. I. Hirota of the Geophysical Institute of Kyoto University for his continuous guidance 
and critical reading of the manuscript. He would like to thank Prof. R. Yamamoto of the Laboratory for Climatic Change Research of Kyoto University for his helpful discussions.

Thanks are also due to Dr. T. Iemori of the World Data Center C2 for Geomagnetism of Kyoto University for providing the auther with the IMF data, to Mr. H. Kobayashi for helping the usage of NMC data and to Mr. F. Hasebe for providing with some programs of the computer. The computations were performed at the Data Processing Center of Kyoto University and at the Laboratory for Climatic Change Research of Kyoto University.

\section{References}

Burns, G. B., F. R. Bond, and K. D. Cole, 1980: An investigation of the southern hemisphere vorticity response to solar sector boundary crossings. J. Atmos. Terr. Phys., 42, 765-769.

Ebel, A., and W. Baetz, 1977: Response of stratospheric circulation at $10 \mathrm{mb}$ to solar activity oscillations resulting from the Sun's rotation. Tellus, 29, 41-47.

- B. Schwister, and K. Labitzke, 1981: Planetary waves and solar activity in the stratosphere between 50 and $10 \mathrm{mbar}$. J. Geophys. Res., 86, 9729-9738.

Hasebe, F., 1980: A global analysis of the fluctuation of total ozone. II. Non-stationary annual oscillation, quasi-biennial oscillation, and longterm variations in total ozone. J. Meteor. Soc. Japan, 58, 104-117.

Heath, D. F., J. M. Wilcox, L. Svalgarrd, and T. L. Dnvall, 1973: Relation of the observed far ultraviolet solar irreadiance to the solar magnetic sector structure. Solar. Phys., 45, 382-403.

Herman, J. R., and R. A. Goldberg, 1978: Sun, Weather and Climate. NASA SP-426.

Hines, C. O., and I. Halevy, 1977: On the reality and nature of a certain sun-weather correlation.
J. Atmos. Sci., 34, 382-403.

Larsen, M. F., and M.C. Kelly, 1977: A study of an observed and forecasted meteorological index, its relation to the interplanetary magnetic field. Geophys. Res. Lett., 4, 337-341.

Nastrom, G. D., and A. D. Belmont, 1978: Preliminary results on 27-days solar rotation variation in stratospheric zonal winds. Geophys. Res. Lett., 5, 665-668.

Roberts, W. O., and R.H. Olson, 1973: Geomagnetic storms and winter time $300 \mathrm{mb}$ trough development in the North Pacific and North Atlantic vorticity. J. Atmos. Sci., 30, 135-140.

Shapiro, R., 1976: Solar magnetic structure and terrestrial atmospheric vorticity. J. Atmos. Sci., 33, 865-870.

Svalgarrd, L., 1976: Interplanetary Sector Structure 1947-1975. Stanford University Institute for Plasma Research report No. 648.

Wilcox, J. M., and D. S. Colburn, 1972: Interplanetary sector structure at solar maximum. J. Geophys. Res., 7\%, 751-756.

-, P. H. Scherrer, L. Svalgarrd, W. O. Roberts, R. H. Olson, and R. L. Jenne, 1974: Influence of solar magnetic sector structure on terrestrial atmospheric vorticity. J. Atmos. Sci., 31, 581-588.

-, L. Svalgarrd, and P. H. Scherrer, 1976: On the reality of a sun-weather effect. J. Atmos. Sci., 33, 1113-1116.

, and P. H. Scherrer, 1979: Variation with time of a sun-weather effect. Nature, 280, 845.

Williams, R. G., 1978: A study of the energetics of a paticular sun-weather relation. Geophys. Res. Lett, 5, 519-532.

—, and E. J. Gerety, 1978: Does the troposphere respond to day-to-day changes in solar magnetic field? Nature, 275, 200-201.

$\longrightarrow$, and 1980: A further study of the tropospheric energetics of a paticular sunweather relation. J. atmos. terr. Phys., 42, 2734.

\title{
惑星間空間磁場境界通過に対する対流圈の応答
}

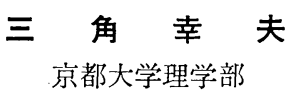

惑星間空間磁場境界通過に対する等圧高度面上の温度・高度の応答を調べた。惑星間空間磁場境界通過は太陽 自転によって起こり, 個々に類似した太陽活動の变化をともなう。1963 年11月から 1978 年 3 月の期間, $20^{\circ} \mathrm{N}$ 以 北, $100 \mathrm{mb}$ 面以下の領域において緯度 $5^{\circ}$ 毎の経度平均場を解析した。

key date analysisによって, 1964年11月〜1972年 2 月間の 12.1.2月に対流圈極域の温度が境界通過日に最小 になっていることが見い出された。 $500 \mathrm{mb}, 90^{\circ} \mathrm{N}$ に扑ける通過日の温度の平均からのずれは $-2.59 \mathrm{~K}$ にな る。これほどの值は1000回繰り返した key date の random sampling によっては得られなかった。

この温度の減少は64〜72年間のどの冬にも，12,1,2月のどの月にも見られる。72年以後に見られないといら点 を除けばこの現象は極めて有意である。 